\title{
Research on the Right to Know of Consumers in the Network Environment CHEN Hongshou
}

Huizhou Economics and Polytechnic College, Huizhou, Guangdong 516057, China

Keywords: Online transactions; the right to know of consumers

\begin{abstract}
With the promotion of Internet technology and the popularity of electronic products, online transactions have developed rapidly in China. Online shopping brings great convenience to consumers. However, due to the virtual nature and technical characteristics of online transactions, online transactions also put consumers in a weak position. The development of the online transaction model has brought new challenges to the protection system of consumer rights and interests, which has caused serious damage to the rights of online consumers. The rights to know of consumers are one of the most important rights of consumers. At present, there are few related studies on the right to know of consumers about online consumers. This paper defines the content of the rights to know of online consumers, expounds the performance and reasons of the intrusion of the right to know of online consumers, and puts forward the idea of establishing and perfecting the legal protection of the right to know of online consumers.
\end{abstract}

\section{Introduction}

The growth in the number of Internet users has provided a large user base for the rapid development of online transactions. Online transactions have won the favor of many operators and consumers for their efficiency and convenience. Online transactions have brought about tremendous changes in the commodity trading market and have had a serious impact on traditional laws. The virtual nature of network operations and consumer subjects makes the behavior of the infringement of consumer rights more complicated. The traditional legal system of consumer rights protection cannot guarantee the safety of network transactions. This paper analyzes the content of the right to know of online consumers and the reasons for the invasion, and constructs a legal system for the protection of the right to know of consumers in the online transactions environment, in order to improve the protection level of the rights and interests of online consumers.

\section{Research on the Right to Know of Consumers in Internet Transactions}

\subsection{The definition of the rights and interests of consumers in network transactions}

The rapid development of online transactions has brought about some new problems. For example, online payment systems, credit evaluation systems, etc. are not sound enough, and violations of the legitimate rights and interests of online consumers have occurred from time to time. The existing legal protection system of consumer rights has gaps in many specific regulations on online transactions. Improving the network trading environment and solving various problems arising from online transactions have become an important issue in protecting consumer rights in online transactions.

Online transactions refer to the way in which the seller issues an offer through the network and the buyer pays the price. Whether the seller of online transactions has legal business qualifications is not clearly defined in the current law. The virtual nature of online transaction subjects has brought new problems to the protection of online consumer rights ${ }^{[1]}$. 
Many of the consumer rights set out in "Law of the PRC on the Protection of the Rights and Interests of Consumers" are only for natural persons. In the traditional way of trading, the scope of buyers and sellers is larger than the consumer category. At present, the specific methods of network transactions are divided into B2B, B2C and C2C. A broadly defined network consumer is a person who accepts paid services provided by network service providers and delivers a certain amount of Internet access fees. In narrow sense, network consumers are limited to online shoppers who purchase certain daily necessities.

B2B is a network platform that provides an Internet display platform to facilitate instant communication among enterprises. Through the Internet platform, many production operators publish transaction information. The $\mathrm{B} 2 \mathrm{~B}$ trading website is currently the main mode of e-commerce application in enterprises. Alibaba is the representative of China's B2B e-commerce website. It is an online trading place for companies. Alibaba website occupies the absolute advantage in the industry. Enterprises or other organizations in the B2B model do not constitute consuming subject. Consumers who are disadvantaged in trading should be specially protected. The purpose of purchasing goods by enterprises or other organizations is to conduct business activities, so they cannot be the ultimate consumers. Therefore, the unit purchaser in the network plus the B2B mode is not protected by the "Law of the PRC on the Protection of the Rights and Interests of Consumers".

$\mathrm{C} 2 \mathrm{C}$ refers to the network transaction mode between individuals. Taobao is currently the largest $\mathrm{C} 2 \mathrm{C}$ trading platform in China. The individual buyer in the $\mathrm{C} 2 \mathrm{C}$ mode is the consumer, as long as there is business operation behavior in the transaction, the business entity is qualified. At present, the problem of fake goods and individual sellers' after-sales service widely existing in the C2C model cannot be adjusted using "Law of the PRC on the Protection of the Rights and Interests of Consumers". Consumers in online transactions should be defined as individuals who purchase goods online or receive services. The business entity should be defined as a legal person or individual organization that sells goods through the Internet.

\subsection{The meaning of the right to know of online consumers}

Consumers need to know whether the product meets their needs before purchasing a certain product. The increasing variety of modern social goods makes it difficult for ordinary consumers to understand them in depth. In order to protect the right to know of consumers, the operator should be required to disclose the information of the goods in a legal form so that consumers can avoid the loss caused by blind consumption for lacking of the necessary understanding.

The online trading process is completely virtual. The online consumer's understanding of the product comes entirely from the operator's introduction of the product. If the operator introduces the real and complete product information, the consumer can make the right decision for his consumption. The comprehensive understanding of commodity information is the premise of making shopping decisions, and it is the protection basis of fair trading rights in consumer rights.

The right to know of online consumers refers to the right of consumers to understand the true and complete information of goods and services when they conduct online transactions. The right to know is the basis for claiming rights when consumers' rights are invaded. Establishing a protection system for the right to know of consumer is conducive to achieving the goal of legal fair value.

A good understanding of the real situation of goods and services is the basis of consumer spending. Only when consumers understand the real situation of goods and services can they make correct judgments on their consumption behaviors and effectively prevent consumer safety accidents. In online transactions, the transaction process between buyers and sellers is carried out through an intangible network. Consumers only understand the product information through 
Internet publicity. It is difficult for consumers to judge whether the information published by the operator is true $^{[1]}$. In online transactions, the law should stipulate that the operator should burden an active obligation, so that the operator is responsible for providing comprehensive and real information about the goods and services.

The statutory rights enjoyed by consumers are the legal obligations of the operator. In online transactions, there are special legal subjects that do not exist in traditional transactions. The rights to know of online consumers have different obligations in each stage in the network transaction. Network operators should provide consumers with real product information in a reasonable way to protect the right to know of online consumers.

Internet transactions need to be based on computer network systems supported by cyberspace technology and transaction services. An online trading platform provider is a third party in a network transaction that provides communication transactions between buyers and sellers, which involves the field of data transmission, etc. Internet trading platform providers should fully protect the right to know of online consumers from the technical management. They should regulate the duty for online platform operators to informing the consumers the disclosure of personal information in order to protect consumers' rights and interests.

\section{The Infringement of the Right to Know of Consumers in Internet Transactions}

\subsection{The types of the right to know of consumers}

At present, China has not yet established a relevant legal protection system to improve the right to know of online consumers. Operators issue false advertisements and other behaviors to make the rights to know of consumers are not guaranteed. False information means that the operator deliberately fabricates business information to deceive consumers. The virtual nature of the network makes the network transaction situation complicated. The common method of publishing false information is the form of advertising ${ }^{[2]}$.

Network operators sometimes deliberately exaggerate product functions for promotional items. The identity of the false advertisement publisher is hard to verify. Advertising has the characteristics of rapid modification, which makes it more difficult for victims to provide evidence and government to supervise. When the operator releases the product information, the business information should be completely released. Sometimes the operator is driven by the interests, and the information that is unfavorable to the operator is blurred. Consumers only choose to purchase based on some information, resulting in a poor gap between the purchase of goods and actual demand.

False credit refers to the good appraisal behavior made by buyers and sellers for the purpose of artificially raising credit, which is not based on real transactions. For example, the operator registers multiple accounts online when the transaction is not made to creates false transaction information, thus falsely promoting the credit rating. The purpose of credit hype is to increase their credit and attract consumers for transactions. Consumers often use the credit rating of the operator as a reference for purchasing goods during online shopping. Some operators make the credit of the hype for the trust of consumers. This behavior violates the right to know of consumers and disrupts the order of the online trading market.

The phenomenon of selling counterfeit and shoddy goods in online transactions is endless. The seller sells counterfeit and shoddy products in the name of a licensed dealer. Counterfeit and shoddy products cannot be used according to normal purposes. The selling price is equivalent to the real commodity price, and the profit margin is large, which causes the illegal operators to make fake sales and sell fakes, which harms the consumers and disrupts the social and economic order. 


\subsection{The reasons for the infringement of the right to know of consumers}

Internet transactions are developing rapidly in China. The payment system and credit system that are compatible with online transactions are not perfect. The high-tech conditions of network technology and the network operators are driven by the interests to ignore the goodwill, so that the right to know of online consumers is infringed.

In online transactions, consumers judge goods through the product information released on the network by operators. Whether the information published by the operator is true is related to whether the right to know of consumers can be realized. Information asymmetry refers to the state of uneven distribution of information between producers and consumers in transactions. One side with an information advantage can take advantage of its dominant position to take opportunistic behavior and damage the interests of the disadvantaged. Driven by interests, network operators make use of information advantages to conceal unfavorable information, which is the internal cause of information asymmetry.

In the traditional trading method, consumers and operators trade face-to-face, and payment and goods delivery are carried out simultaneously. In online transactions, consumers cannot directly see physical goods. Operators and consumers conclude electronic contracts through the Internet, requiring payment first. The separation of payments from the delivery of goods creates a trading time gap that allows some unscrupulous operators to use false information to defraud consumers ${ }^{[3]}$.

The way of online trading greatly facilitates people's lives. Whether it can effectively protect the legitimate rights and interests of online consumers is related to the sustainable development of the online trading market. China's current consumer rights protection legal system is based on "Law of the PRC on the Protection of the Rights and Interests of Consumers", and it involves less protection of the rights to know of online consumers. The "Electronic Signature Law of the People's Republic of China" gave the legal effect of electronic signature for the first time and laid the foundation for promoting the safe development of online transactions.

In 2010, the State Administration for Industry and Commerce promulgated the "Interim Measures for the Administration of Online Commodity Transactions and Related Behaviors". It provides the protection of the right to know of consumers from the aspects of market access, the protection of legal rights and interests of network consumers and operators. China's protection of the right to know about online transactions has been introduced by the department, but no relevant laws and administrative regulations have been formulated. In the network transaction mode, China's institutional legislation on the protection of the right to know of consumers is still blank, which affects the realization of the right to know of online consumers.

\section{Protection measures for the right to know of online consumers}

The clear rights of online consumers and the increase of operators' participation obligations are the trend of legislation on the protection of online consumer rights. In the construction of the network consumer rights protection legal system, we should promote the honesty management, promote fair trade, and timely establish a suitable consumer protection right protection system to ensure the healthy development of online transactions ${ }^{[4]}$.

The law should stipulate that when the consumer and the operator are in the contract, the operator should provide real information about the goods and services, and different technical means are required to enter into a contract. Goodwill is an important basis for consumers to make purchasing decisions. Credit evaluation is an effective way to prevent trading risks. The establishment of a credit system can prevent the invasion of the right to know of consumers. Therefore, a sound commercial credit evaluation system should be established. We should 
formulate the law to establish a credit evaluation mechanism as soon as possible. At present, there is no law on credit evaluation mechanism in China, and relevant laws can be introduced to regulate online trading behavior.

In online transactions, both parties trade in an invisible network environment. Consumers and operators are not necessarily online at the same time. The provision of passive disclosure obligations of network operators as an active disclosure obligation is conducive to the realization of the right to know of consumers in online transactions and to meet the needs of consumers to obtain commodity information ${ }^{[5]}$.

Evaluating the credit rating of network operators allows consumers to directly understand the business reputation of the operator. The high evaluation of credit rating has a positive effect on the improvement of the performance of the operators. The credit rating mechanism has a preventive effect. It helps to increase the success rate of online transactions. A third party authorized by the government should be established to evaluate the credit of the network operator. In the network environment, consumer associations should collect and analyze information such as consumer complaints to evaluate operators' network operations, and motivate them to adjust their business strategies to protect the realization of the right to know of online consumers.

\section{Conclusion}

With the popularity of computer network technology, online transactions have changed the traditional market trading model. Online transactions have broken through the limitations of time and space and are gradually accepted by more consumers. Online transactions also bring great consumption risks to consumers. The right to know is the premise of rational consumption of online consumers. Fully guaranteeing the right to know of consumers is of great significance to maintaining the economic order of the network market and building a harmonious society. In view of the current problem of the invasion of the right to know of consumers in China's online transactions, we should learn from the successful legislative experience of other countries on the protection of the right to know of consumers, establish a network consumer information acquisition system, and establish a network transaction credit evaluation mechanism, in order to adapt to social development, to achieve the protection of the right to know of network consumers.

\section{References}

[1]Zhaojie Li. Research on Legal Issues of Network Consumer Rights Protection[D].Anhui University of Finance and Economics,2014.

[2]Yafei Zhang. Research on the Right to Know of Consumers in E-commerce[D].Hebei University,2012.

[3]Beibei Zhang. Research on Legal Issues of the Right to Know of Online Shopping Consumers[D].Hebei University,2017.

[4]Jingjing Chen. Research on the Protection of Consumers' Online Rights and Interests[D].Yantai University,2017.

[5]Jing Chen. Research on Legal Protection of the Right to Know of Internet Consumers[D].Guangxi Normal University,2017. 